\title{
O papel das mulheres no sistema creditício da freguesia de Guarapiranga: o caso de Dona Francisca Januária de Paula Carneiro
}

The role of women in the credit system of the parish of Guarapiranga: Dona Francisca Januária de Paula Carneiro's case

Rodrigo Paulinelli de Almeida Costa

https://orcid.org/0000-0003-0031-0685

Universidade Federal de Minas Gerais

\begin{abstract}
Resumo: O objetivo desse trabalho é investigar a formação do espaço nas vertentes dos rios Piranga e Pomba, a partir de uma análise braudeliana dessa região, assim como do papel das mulheres no sistema creditício. Para fazer essa investigação, é necessário atentar-se para as dinâmicas sociais, econômicas, familiares que norteiam a construção desse espaço, analisando, conjuntamente, as relações humanas que contribuem para a sua formação. Segundo Rogério Haesbaert, "O papel do espaço, pode ser interpretado tanto como rugosidades ou constrangimentos, que redirecionam os processos sociais e econômicos, quanto como referenciais inseridos na vida cotidiana e que perpassam nossas identidades coletivas" (HAESBAERT, 2002, p.81/82). Após entender de que forma o espaço mineiro e principalmente da freguesia de Guarapiranga foi se constituindo, buscará conhecer de que forma o sistema de crédito influenciava a economia da região. Assim como perceber a importância da Dona Francisca Januária de Paula Carneiro, uma proeminente mulher, vinda de uma família sem muito prestígio social, que se casa com um membro de uma das mais importantes famílias da região e após ficar viúva, por méritos próprios consegue expandir os negócios da família e multiplicar a sua riqueza.
\end{abstract}

Palavras-chave: Minas Gerais. Século XIX. Sistema de crédito.

Abstract: The aim of this work is to investigate the formation of space on the slopes of the Piranga and Pomba rivers, based on a Braudelian analysis of this region, as well as the role of women in the credit system. In order to carry out this research, it is necessary to look at the social, economic and family dynamics that guide the construction of this space, analyzing jointly the human relations that contribute to its formation. According to Rogério Haesbaert, "The role of space can be interpreted as roughness or constraints, which redirect social and economic processes, as well as referential elements inserted in daily life and that permeate our collective identities" (HAESBAERT, 2002, p.81 / 82). After understanding how the mining area and mainly the parish of Guarapiranga was becoming, will seek to know how the credit system influenced the economy of the region. As well as realizing the importance of Dona Francisca Januária de Paula Carneiro, a prominent woman, coming from a family without much social prestige, who marries a member of one of the most important families of the region and after being a widow, by own merits can expand the family business and multiply their wealth.

Keywords: Minas Gerais. XIX Century. Credit System.

Segundo Marc Bloch, a "História é a ciência dos homens no tempo" (Bloch, 2005, p.55). No entanto, é impossível pensarmos na relação homem/tempo, sem considerar 
que ela ocorre em um espaço específico. Posso dizer então, completando a máxima do historiador francês, que a História é a ciência dos homens no tempo, interagindo e modificando o espaço que o circunda. Partindo dessa premissa, e considerando que "toda a divisão territorial é uma divisão social, na medida em que nela se alojava uma sociedade de dimensões variáveis, encontrando nela ao mesmo tempo os seus limites e a sua razão de ser, vivendo prioritariamente de suas próprias ligações internas" (Braudel, 1989, p. 58-59).

Os chamados Sertões do Leste foram extremamente importantes para a construção da sociedade mineira, uma vez que servia como caminho de passagem entre o Rio de Janeiro e Minas Gerais, passando pelo Caminho Novo. Além disso, dentro desse espaço se constituiu uma importante freguesia do leste mineiro entre o final do século XVIII e meados do século XIX, a freguesia de Guarapiranga. Durante a primeira metade do XIX, essa freguesia era a maior dessa região com aproximadamente dez mil habitantes. Piranga foi uma importante fronteira agrícola da região de Ouro Preto e Mariana, recebendo um intenso fluxo migratório após a decadência da mineração, contando com importantes figuras políticas para a sociedade mineira durante o século $\mathrm{XIX}$.

\section{A formação do espaço mineiro e da freguesia de Guarapiranga}

A formação do espaço da Capitania de Minas Gerais ocorreu antes mesmo da sua fundação no ano de 1720. Em 1701 Domingos Couto André recebeu uma sesmaria em Paraopeba, no local onde sediaria a Freguesia de Nossa Senhora da Conceição das Congonhas na comarca do Rio das Velhas. Em seu pedido, o requerente diz:

Eu, Gomes Fernandes de Andrade os faço saber e segue esta carta de sesmaria a virem que sendo de respeito a mil setecentos e um por sua petição Domingos Andre Coutto, que me se achava na grande fabrica de escravos e bastante família e como dava sustento de sua carência de terras em que poder plantar mantimentos, procurara manos devolutas e desocupados na Paraopeba freguesia de Nossa Senhora da Conceicao de Congonhas, os guias partião com roca de Carlos de Abreu David, Joao Luis Teixeira de Carvalho e posses de Manoel Teixeira Da Cruz aonde surgia fabricas de sua roca, fazendo divisão entre dois córregos pequenos, que estão juntos um do outro por cima do Caminho que vai para a roca de Carlos de Abreu, e porque para reunir as ditas terras conjunto titulo e sem contradição de pessoa alguma me pedia demanda-se dellas passar carta de sesmaria na forma das ordens de Sua Majestade, ao que atendendo eu, e a atividade que se segue na Fazenda Real legue responsável as terras desta Capitania. Eu por bem fazer mercê ao dito Domingos Andre Coutto, em nome do dito informo meia legoa de terras em quadra na referida margem dentro das confrontações acima mencionadas com declarações porem que seja obrigado dentro de um ano que se conversado com os vizinhos com quem divide cultivar a terra. (Arquivo Público Mineiro, Seção Colonial. Códice 72 página 186. Grifo meu.)

Como se observa na concessão acima, um dos principais objetivos da doação de sesmarias era, além de ocupar o território, tornar essa terra produtiva. Um ano antes da concessão dessa primeira sesmaria, é noticiada a descoberta de ouro na região do Rio das Velhas e houve várias expedições para a exploração do local. Dessa forma,

\footnotetext{
${ }^{1}$ Em sua tese de doutorado Mateus Rezende analisa essas proeminentes figuras políticas da região da freguesia de Guarapiranga. ANDRADE, Mateus Rezende de. Compadrio e posse da terra: da produção do espaço às hierarquias sociais (Vale do Rio Piranga, Minas Gerais, 1804 - 1856. Tese doutorado UFMG 2018.
} 
seria extremamente importante à coroa portuguesa ocupar essa região para explorar da melhor forma possível os recursos econômicos do local. Com isso, ocorre o processo de ocupação em Minas Gerais. Inicialmente ocupado nas regiões mineradoras e suas adjacências, posteriormente essa ocupação de expande para as demais regiões da Capitania.

Além disso, é importante entender de que forma esse espaço vai se transformando e suas fronteiras vão gradualmente se modificando. As fronteiras podem ser entendidas como "extremidade de um país ou uma região do lado onde confina com outro. Tal noção parece ser equivalente à de limite: linha de demarcação separando territórios ou terrenos contínuos" (Hissa, 2002, p.36). Apesar de ser uma região de contato/separação entre locais contínuos, essas fronteiras não são fixas e podem se mover livremente, tanto para um lado quanto para o outro. É exatamente o que pode ser observado para a região das Minas Gerais, de um local desocupado, gradualmente essa fronteira vai se expandindo até formar o estado de Minas Gerais como conhecemos hoje.

O desenvolvimento do espaço mineiro apresentou essa particularidade em relação às demais capitanias do Brasil. Primeiramente se desenvolveu o caráter urbano para posteriormente ocupar o rural. Essa diferença se deu devido à mineração, não foi uma ocupação planejada, nem surgiu a partir de uma vontade manifesta da Coroa Portuguesa. Esse espaço urbano mineiro teria sido, segundo a visão de Cunha construído a partir da sobreposição de processos distintos, mas complementares. "Esses espaços vão se superpondo na construção dos primeiros arraiais auríferos, sendo que a eles se somariam logo os lugares de sociabilidade, associada à vivência religiosa das irmandades laicas, assim como as estruturas próprias da institucionalização do poder, o estabelecimento dos instrumentos de justiça" (Cunha, 2009, p.63).

Apesar do arraial ser a unidade básica de desenvolvimento espacial de Minas Gerais e a urbanidade ser a característica particular dessa capitania em relação às demais no Brasil colonial, no entanto, a demarcação dessa fronteira entre o rural e urbano $^{2}$ nunca foi algo fácil de se delimitar. José Newton Meneses argumenta que

se falamos de uma vila setecentista de Minas Gerais, não temos como nos limitar à sua demarcação arruada sem considerar o diálogo com o entrono rural ou mesmo com a ruralidade presente no interior do seu traçado urbano. $O$ limite entre o rural e o urbano, aliás é algo pouco percebido ou de difícil caracterização para as Minas setecentistas. Casas e quintais, formas de trocas e de relações de vizinhanças, enfim, formas de viver, distinguem pouco esses dois espaços que artificialmente

\footnotetext{
${ }^{2}$ A oposição entre o rural e o urbano pode ser vista também no artigo escrito por Pedro de Almeida de Vasconcelos "A cidade, o urbano e o lugar". Nesse artigo, Vasconcelos apresenta um breve estado da arte sobre esses três conceitos que apresenta no título. Para o autor, "a cidade é uma aglomeração de objetos e indivíduos, um território particular, uma sociedade específica” (p. 12). O urbano por sua vez aparece como antônimo de rural. O autor determina que "o urbano é utilizado em oposição ao rural e por extensão, indica a qualidade de um comportamento controlado e designa o habitante das cidades". (p. 13) Para finalizar seu texto, ele ainda argumenta que "com o desenvolvimento das novas formas dos aglomerados urbanos, seja através de nebulosas urbanas, seja através do crescimento de aglomerações desmesuradas como Los Angeles, os conceitos de urbano e de cidade estão sendo cada vez mais contestados: é quase impossível constatar onde termina uma grande cidade, e mesmo estabelecer a especificidade do urbano neste final de século [XX]" (p. 15). VASCONCELOS, Pedro de Almeida. "A cidade, o urbano e o lugar". In: Revista GEOUSP. $n^{\circ} 6$. São Paulo, 1999. A parte da historiografia que estuda a história das cidades e da construção do espaço urbano é um ramo muito estudado atualmente. No entanto, não é meu interesse, nesse momento, me aprofundar nessas discussões. Fiz esse adendo para demonstrar a complexidade e a particularidade do espaço mineiro.
} 
Essa hierarquia urbana também cria uma separação entre a urbe e o sertão. Pensando nessa separação, é preciso entender de que forma os conceitos de fronteira e limite se inserem nessa discussão. As fronteiras podem ser tanto físicas (uma serra, um rio), psicológicas (ignorância relativa a determinado assunto), temporais (diferentes temporalidades que separam determinados acontecimentos). Elas podem designar a separação ou a barreira entre dois elementos, mas também continuidades. $O$ tempo e o espaço, por exemplo, são ao mesmo tempo íntimos nas continuidades e nas rupturas.

Cássio Hissa, em seu livro a Mobilidade das Fronteiras analisará de que forma as fronteiras físicas e as fronteiras do conhecimento são construídas. O argumento central de seu livro é o de que as fronteiras são móveis e que só é possível a existência de diálogos interdisciplinares a partir do momento em que sejam bem definidos os espaços (intelectuais) de cada disciplina e quais os limites e as barreiras existentes entre elas.

A mobilidade das fronteiras referentes ao conhecimento assume o significado da democratização de discursos. Somente assim há como imaginar um diálogo interdisciplinar possível (do qual a sociedade possa também participar efetivamente) e uma leitura digna da complexidade do mundo, frequentemente inibido por instituições - incluindo, contraditoriamente a universidade - que em muitas circunstancias até mesmo impedem o trânsito do pensamento que almeja a liberdade. (Hissa, 2002, p. 15)

As fronteiras apresentam uma ideia de finitude, sendo uma linha imaginária que divide os territórios (Hissa, 2002, p. 34). Possuem uma conotação políticoadministrativa, em que governos e instituições de poder dividem e criam espaços demarcados para as suas jurisdições.

Elas não apresentam a ideia de algo intransponível, muito pelo contrário. Devem ser transpostas, ampliadas. Dentro do espaço mineiro a todo tempo é possível observar a mobilidade dessas fronteiras. A separação entre a urbe e o sertão foi se alterando ao longo de todo o século XVIII e XIX. No códice de Costa Matoso, é possível observar essa mobilidade. O que é chamado de sertão incógnito em 1703, em pouco mais de 30 anos se constituirá a freguesia de Guarapiranga.

Nestes mesmos princípios, que foram na era de 1702 para o de 1703 não descansando o dito coronel com diligências de ampliar descobrimentos, mandou a seu filho Bento Fernandes Furtado a bandeirar para a parte do sul do ribeirão do Carmo, pelo sertão incógnito que se achava entre o Ribeirão e Guarapiranga , e gastando meses nesta diligência descobriu várias "faisqueiras pelos lugares chamados Pinheiro, Rocha, Bacalhau, Pirapetinga; e voltando com soldados e escravos em rede., picados de cobras e bichos venenosos, com muito trabalho, fomes e riscos de vida, não deu a partilhas estes descobrimentos por serem as "pintas limitadas. Seguindo, porém, as suas picadas, foram entrando outros mineiros que, lavrando estas faisqueiras, foram achando aumento nelas, razão por que foram povoando sítios, arraiais, capelas, freguesia, com muita utilidade dos povos e da Real. Fazenda de Sua Majestade ${ }^{3}$.

Um importante historiador que também analisa essa a questão foi Sérgio Buarque de Holanda. Em seu livro Caminhos e Fronteiras, analisa o processo de

\footnotetext{
${ }^{3}$ Bento Fernandes Furtado, Minas Gerais, 1750. "Notícias dos primeiros descobridores das primeiras minas do ouro pertencentes a estas Minas Gerais, pessoas mais assinaladas nestes empregos e dos mais memoráveis casos acontecidos desde os seus princípios" In: CÓDICE COSTA MATOSO. Op. Cit. p. 182.
} 
formação do espaço paulista, fazendo um diálogo entre as tradições indígenas, os conhecimentos portugueses e a miscigenação dos conhecimentos transmitida pelos bandeirantes. Um argumento central para a escrita do livro foi a questão da fronteira. Para o autor

Se o aceno ao caminho que convida ao movimento, quer apontar exatamente para a mobilidade característica das populações do planalto paulista o fato é que essa própria mobilidade é condicionada entre elas e irá condicionar a situação implicada na ideia de fronteira. Fronteira bem entendido entre paisagens, populações, hábitos, instituições, técnicas, até idiomas heterogêneos que aqui se defrontavam, ora a abastecer-se para deixar lugar à formação de produtos mistos ou simbólicos, ora a afirmar-se, ao menos enquanto não superasse a vitória final dos elementos que se tivessem revelado mais ativos, mais robustos ou melhor equipados. (Holanda, 1975, p. 8)

Essa mobilidade das fronteiras em Minas Gerais também foi estudada por Cláudia Fonseca. De acordo com a autora, em pouco tempo o sertão ocupado somente por índios de diversas nações foi profundamente transformado por homens em busca do enriquecimento rápido. "Na região mineira, bastaram alguns decênios para que se desenrolassem processos de grande complexidade, que em outras fronteiras da colônia levaram muito mais tempo para se realizar: a gênese e o desenvolvimento das cidades, a constituição de fluxos comerciais" (Fonseca, 2011, p.57).

Cássio Hissa, cria comparações entre os termos fronteira e limite. Para ele, na questão territorial, o limite está voltado para dentro, ou seja, a área ocupada pelo território, enquanto a fronteira está voltada para fora, ou seja, ela está "olhando" até onde poderá se expandir. O limite estimula a ideia de distância e separação, enquanto a fronteira movimenta a reflexão sobre o contato e a integração (Hissa, 2002, p. 34).

Assim, é possível observar que as fronteiras e os limites possuem significados diferentes. O limite remete a uma ideia de separação entre dois elementos que estão em contato e que existe uma linha divisória entre eles. Essa linha pode ser um marco físico (o rio que separa duas propriedades), ou algo que remeta também ao cerceamento da liberdade (uma lei, uma regra, uma imposição). O limite é um conceito criado pelo ser humano para facilitar o domínio dos espaços. Assim sendo, limite nos remete a uma ideia de barreira. Na natureza, não existem limites definidos para o clima, para o relevo ou para a vegetação. Na separação entre o cerrado e a caatinga por exemplo, existem as zonas de transição, em que se observa, gradualmente a mudança de um tipo de vegetação para o outro.

\section{A economia guarapiranguense e o sistema creditício}

Situada na Zona da Mata mineira, dentro da Bacia do Rio Doce a tranquila cidade de Piranga, localizada a 170 quilômetros de capital Belo Horizonte, com 17.323 habitantes, segundo o censo do IBGE de 2010, já foi a maior e mais importante localidade dessa região. Localizada nos sertões do Leste, a vila de Guarapiranga teve sua fundação no início do século XVIII, mais precisamente em 1705 , graças à descoberta de ouro na região. Desde as primeiras bandeiras de descobrimento a região recebeu um intenso fluxo migratório. A partir da segunda metade do século XVIII, devido à exaustão das lavras, a freguesia passou a se dedicar às atividades agropastoris.

Com a decadência da mineração em Minas Gerais, a freguesia de Guarapiranga, por se encontrar em uma zona de fronteira agrícola recebeu outro grande fluxo 
migratório, contando no início do século XIX com aproximadamente 10.000 habitantes. Como demonstra Gusthavo Lemos, o mundo piranguense era composto por duas características principais: diversificação econômica interna e uma relativa autosufuciência das unidades agrícolas de médio porte. Esses fatores foram primordiais para que Guarapiranga, no século XIX, se tornasse o principal fornecedor de açúcar e cachaça de Minas Gerais, trazendo riqueza e prosperidade para a região (Lemos, 2012).

No início do século XIX a freguesia de Guarapiranga era composta por 11 distritos de paz listados nas listas nominativas de 1831: Santo Antônio do Bacalhau, Nossa Senhora do Rosário do Brás Pires, Santo Antônio do Calambau, Conceição do Turvo, Dores do Turvo, Nossa Senhora da Conceição do Manja Léguas, Mestre Campos, Nossa Senhora da Oliveira, Piranga e Tapera (Andrade, 2014). No mapa elaborado por Andrade, é possível observar os limites da freguesia (Imagem 1).

\section{Imagem 1 - Freguesia de Guarapiranga - Distritos de Paz, Listas Nominativas de} 1831 e 1832.

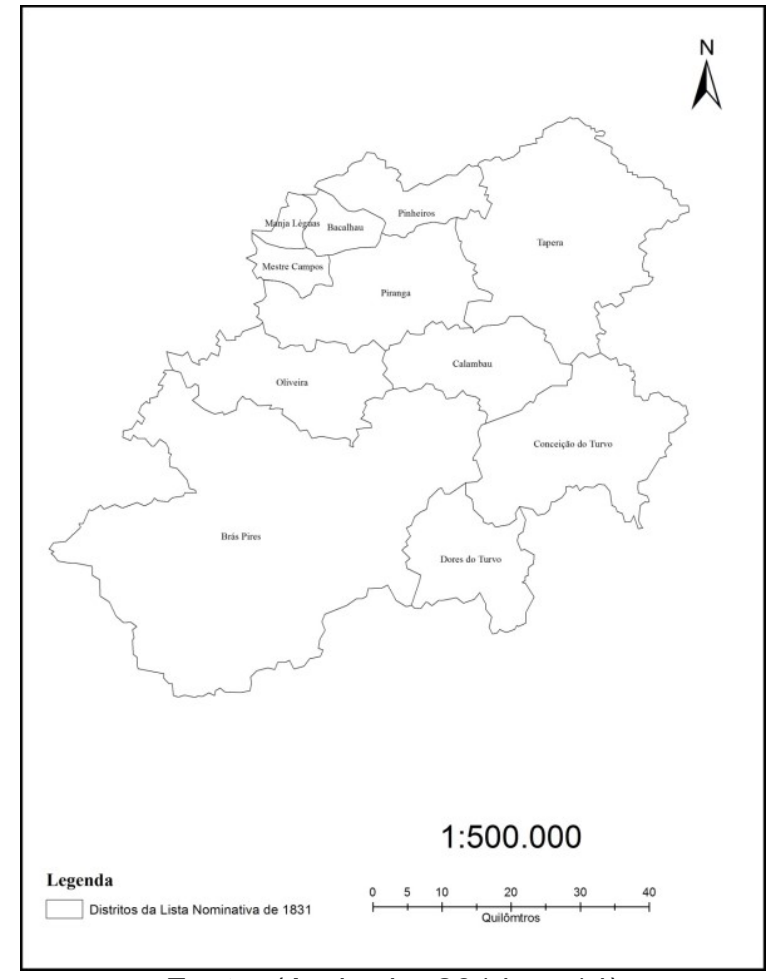

Fonte: (Andrade, 2014, p. 14)

Para o conhecimento da composição populacional de Guarapiranga foram utilizadas as listas nominativas de 1831/32. As listas nominativas eram documentos solicitados pelos presidentes de província, nos quais constava a relação nominal de todos os habitantes de um domicílio. Essas listas tinham como objetivo mapear a realidade nacional (Paiva, 1990, p. 90-91). Em 18314, a população piranguense era de 10.928 indivíduos. Destes indivíduos, 3.345 eram homens livres residentes na freguesia de Guarapiranga; as mulheres somavam 3.721; já em relação à população escrava, observa-se a presença de 2.390 homens e 1.472 mulheres.

A população da freguesia de Guarapiranga se concentrava no campo, devido à intensa produção de gêneros agrícolas que a freguesia produzia. A população rural

${ }^{4}$ Foi escolhido o ano de 1831 para a análise devido a realização das listas nominativas. 
representava $54 \%$, contra $19 \%$ da população urbana e $27 \%$ dos fogos pesquisados não continham informações sobre a sua condição. De acordo com Fábio Faria Mendes, a freguesia de Piranga, vivenciou um processo de "acomodação evolutiva" que acompanhou a transição de uma economia mista de lavras e roças em fins do século XVIII, para uma economia ruralizada e centrada na produção mercantil de alimentos (Mendes, 2011, p.14).

Graças à intensa migração na segunda metade do XVIII a população se especializou no cultivo e transformação da cana-de-açúcar, produzindo em grande quantidade açúcar e cachaça que era comercializada com a região mineradora de Ouro Preto e Mariana. "Dessa forma, despontaram grupos sociais envolvidos nessa atividade, seja como plantadores de cana, pequenos aguardenteiros ou grandes senhores de engenhos, uma verdadeira elite rural" (Andrade e Lemos, 2013, p. 31).

Além da produção de aguardente, existiam também criadores de gado vacum que serviam tanto para a alimentação da população, como também tração, tanto para cargas, quanto para movimentar os engenhos. De acordo com Lemos (2012, p. 26):

[Essas fazendas] comportavam as ferramentas para o trato dos cultivos e das lavras e as benfeitorias necessárias para a transformação da cana (em aguardente, açúcar e/ou rapadura) e da mandioca, bem como algumas aparelhagens para a confecção das rudes vestimentas da escravaria; possuíam, ainda e finalmente, tendas de ferreiro e as estruturas de armazenamento das safras. Portanto, essas fazendas detinham as ferramentas, o maquinário e as construções necessários para sua autosuficiência (o que não quer dizer que as famílias não importavam produtos de outras localidades, mesmo do exterior).

Roberto Borges Martins afirma que a economia de Minas Gerais no século XIX, diferentemente de províncias como São Paulo e Bahia, não possuía em sua unidade produtiva grandes plantations com grandes planteis de escravos. Douglas Libby demonstra em seu trabalho que mesmo a sociedade mineira tendo a maioria dos proprietários não escravistas, o escravismo se enraizou profundamente na sociedade, na medida em que conta com uma grande quantidade de pequenos proprietários de escravos (Libby, 1988).

A freguesia de Guarapiranga não fugia à regra. A grande maioria da população livre não possuía escravos, e os que possuíam tinham em média um plantel de até nove escravos. De acordo com Gusthavo Lemos, o tamanho das unidades produtivas e de seus respectivos contingentes de escravos, em Guarapiranga, era raro encontrar fazendas que comportassem mais de 35 escravos (Lemos, 2012, p. 29).

A prática do crédito foi muito recorrente na tentativa de suprir a baixa disponibilidade monetária em Minas Gerais ao longo do século XIX. Na freguesia de Guarapiranga, percebemos a disseminação dessa prática. Para a análise do sistema creditício, foram analisados somente os inventários post-morten, mas é importante salientar que é possível encontrar dívidas ativas ou passivas em cartas de crédito e em livros de compra. É preciso ter cuidado ao fazer generalizações, uma vez que dívidas podem não ter sido anotadas ou podem ter sido pagas enquanto o inventariado ainda era vivo. Portanto, as conclusões que serão tomadas são referentes às análises das fontes que estavam disponíveis.

Francisca Januária de Paula Carneiro, viúva, era comerciante na Vila de Piranga, dona de uma loja de fazenda seca, possuía 140 devedores. Em vários casos, encontramos a descrição da dívida, com as condições de pagamento. "Item e afim mais foi feito pelo mesmo Inventariante appresentando hum credito de numero cincoenta e 
dous que deve o Tenente Romualdo Lopes da Crus passado a nove de Agosto de mil oito centos e sessenta e hum pelo prazo de seis meses e na falta do premio na quantia de seis centos ao ano (com recibo) principal conforme a conta feita n'elle da quantia de cento e vinte nove mil e oitocentos reis com o que se sabe" ${ }^{5}$. Percebe-se que, caso o Tenente Romualdo não pagasse a dívida em até seis meses da data do empréstimo ele deveria pagar juros de seiscentos réis ao ano.

A cobrança de juros sobre as dívidas era corrente, porém não muito encontrado. Dos inventários analisados, apenas naqueles de pessoas ligadas ao comércio que é encontrado esse tipo de cobrança. No entanto, nem todas as dívidas desses comerciantes possuem cobrança de juros. O número de dívidas por inventário é relativamente pequeno. Como se pode observar na tabela 1, a maior parte dos documentos (69\%) apresentavam um número de 10 ou menos dívidas.

Tabela 1 - Número de dívidas por inventário, Guarapiranga, 1830-1865

\begin{tabular}{|c|c|}
\hline Faixa de dívidas por inventário & Número de inventários \\
\hline $1-5$ & 10 \\
\hline $6-10$ & 10 \\
\hline $11-15$ & 2 \\
\hline $16-20$ & 3 \\
\hline$>20$ & 5 \\
\hline
\end{tabular}

Fonte: Inventários do Arquivo do Fórum de Piranga.

Os valores, em geral também não eram muito elevados. Segundo Carlos de Oliveira Malaquias, "as dívidas de baixo valor eram referentes a compras a prazo (contas de rol de livro) e funcionavam como um substituto do dinheiro, enquanto os maiores valores poderiam representar algum tipo de capital financeiro ou transações de meios de produção" (Malaquias, 2014, p. 180-181).

O universo creditício de Guarapiranga fugia à regra daquilo que a historiografia dita. Os trabalhos sobre o crédito dizem que os comerciantes e as pessoas vinculadas a esse universo creditício contraem dívidas passivas com comerciantes maiores e, com esse dinheiro, criam seu mercado credor, fazendo com que esse dinheiro que foi emprestado seja repassado a outros indivíduos.

Enaile Flauzina Carvalho, observando o sistema creditício dos comerciantes de Vitória no século XIX chegou à conclusão que: "A disponibilidade de conceder empréstimos e vendas a prazo, servia para firmar relações com uma considerável porção da população, enquanto a tomada de empréstimos acabava por garantir estabilidade e/ou recuperação financeira dos comerciantes" (Carvalho, 2013, p. 164).

Afonso de Alencastro Graça Filho, por sua vez, também estudando os comerciantes e os homens ricos de São João Del Rei no período de 1831-1888, observa, em relação a um desses comerciantes, que:

Três dívidas passivas foram feitas na praça do Rio de Janeiro (1:732\$098), duas com as firmas comercias Rocha\&Filho $(1: 373 \$ 030)$ e a casa de importação/exportação Cleggs\&Irmãos (14\$668) [...] Pelo visto, ao mesmo tempo em que o comendador Francisco de Paula cedia pequenas quantias aos seus clientes democratizando o acesso ao crédito, recorria a financiamentos de maior

\footnotetext{
${ }^{5}$ Inventário post-mortem da Dona Francisca Januária de Paula Carneiro. Localizado no Arquivo do Fórum de Piranga- MG. Ano 1865, Códice A037, Auto 469.
} 
porte junto a firmas comerciais e familiares. (Graça Filho, 2002, p. 73)

Os grandes comerciantes e as pessoas vinculadas ao sistema creditício, assim como o Comendador Francisco de Paula, em São João Del Rei recorriam aos comerciantes de grosso trato e empresas particulares da cidade do Rio de Janeiro, como forma de "aumentar" a quantidade de dinheiro disponível para a concessão de empréstimos no principal distrito da comarca do Rio das Mortes.

Dessa forma, é possível concluir que a dinâmica creditícia em Guarapiranga era autárquica, em que o dinheiro e as relações se concentravam dentro desse universo de confiança e de controle social. A partir das análises dos inventários, não encontramos dívidas ativas dos grandes fornecedores de crédito com outras pessoas que não aquelas inseridas dentro desse universo.

\section{As redes de crédito: o caso da Dona Francisca Januário de Paula Carneiro}

A análise de redes sociais procura estabelecer padrões relacionais entre atores de uma mesma natureza, como as relações de crédito entre os indivíduos na freguesia de Guarapiranga, chamadas de redes one-mode, ou entre atores de natureza diferentes, como as relações entre jogadores de futebol de uma determinada liga e a suas respectivas nacionalidades, chamadas de redes two-mode. Nesse trabalho, me preocuparei somente com as redes one-mode.

Por mais que o crédito não fosse a principal atividade econômica da freguesia, é possível perceber, como dito anteriormente, vários indivíduos que contraiam dívidas com mais de um credor. E graças a essas repetições foi possível visualizar várias redes que se formaram entre esses atores. Graças a essas redes, é possível também entender como essa sociedade funcionava, através das outras redes de sociabilidade e estratégias de "controle social" que são construídas.

Para a construção dessas redes, ao analisar os inventários, procurei por nomes que se repetiam. Como existem vários nomes iguais, me preocupei em analisar as listas nominativas de 1831/32, assim como o ano em que esse nome é repetido para tentar afirmar que aquele era o mesmo indivíduo. Indivíduos que apareciam em inventários de pessoas da mesma família, ou inventários de pais e filhos, ficaram mais fáceis de identificar, ainda mais quando a dívida era transmitida.

Em um primeiro momento, foi construído um banco de dados no Excel, utilizando as seguintes variáveis: Código do inventário; Ano do Inventário; Local em que o inventário foi feito (assumi a partir dessa informação que aquele local seria a residência do inventariado, uma vez que grande parte dos seus bens ali estava); Freguesia; Nome do inventariado; Nome do Credor; Patente do credor (caso houvesse); Nome do devedor; Patente do devedor (caso houvesse); o valor das dívidas. Após elencar todos os atores, exportei esse banco de dados para o software Pajek do qual surgiram às redes que analisaremos a seguir.

Essa rede formada dentro da freguesia, encontram-se alguns atores que contraem crédito com mais de um inventariado. Ao contrair crédito com mais de um ator, é possível observar as estratégias sociais dentro da sociedade. Essas estratégias podem ser tanto de confiança entre parentes, como os pais e filho, Capitão Antônio Teixeira Guimarães e Tenente Antônio Teixeira Guimarães, ou manutenção de prestígio social como os Vidigal de Barros e os Carneiro. Andrade (2014), já observa isso em relação ao compadrio e ao casamento: 
Vê-se por esses enlances matrimoniais que os Sande Barros [depois chamados de Vidigal de Barros] arquitetaram importantes relações com famílias da freguesia de Guarapiranga que detinham amplo cabedal. Não obstante, estes enlaces expressam formas como este grupo familiar geriu seu patrimônio através da mobilidade sócio-espacial dentro do território da freguesia. [Ao se tornar herdeiro da fazenda d'O Seringa em Calambau, Antônio Pedro Vidigal de Barros] começou a mover recursos para se assentarem nesta nova localidade e assim, casam-se estrategicamente com os Carneiro Miranda. (Andrade, 2014, p. 91)

Na imagem 2, após a retirada dos indivíduos que não estabeleciam relações com mais de um inventariado, é possível observar de forma mais detalhada como se estabeleciam as redes de crédito entre as famílias de maior proeminência social dentro da freguesia de Guarapiranga.

Imagem 2 - Rede de crédito, Guarapiranga, 1830-1865

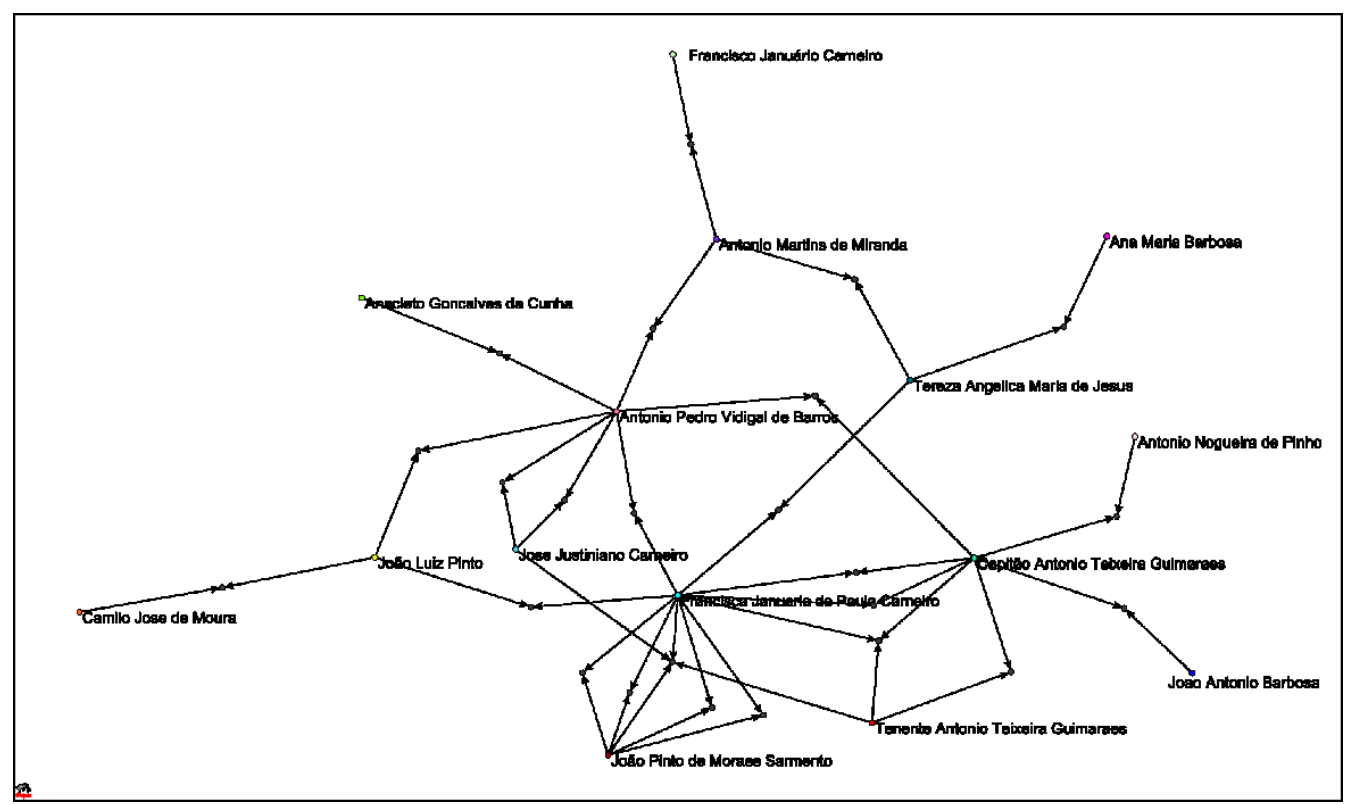

Fonte: Inventários post-mortem do AFP

A centralidade é um conceito da Análise de Redes Sociais que mede a importância de um sujeito dentro da rede. Os atores proeminentes são aqueles que estão intensamente envolvidos em relações sociais com outros atores. Esse envolvimento o torna mais visível dentro das redes do que os demais. O ator central é aquele que é alvo de inúmeros laços, sejam chegando até ele, ou partindo dele (Wasserman e Faust, 1994).

O grau de centralidade de um indivíduo dentro de uma rede pode ser calculado a partir do Input, ou seja, do número de laços que chegam até o ator, ou do Output, o número de laços que dele partem. Como a rede de crédito de Guarapiranga é unidirecional, ou seja, os atores centrais só fornecem crédito, será medido apenas o Output desses indivíduos. Nas tabelas 11 e 12, observamos o grau de centralidade e o número de relações que cada inventariado da rede refinada 2 estabelece com os "indivíduos pontes". 
Tabela 2 - Grau de centralidade ${ }^{6}$ dos inventariados, Guarapiranga, 1830-1865.

\begin{tabular}{|l|l|}
\hline Inventariado & Grau de Centralidade \\
\hline Francisca Januária de Paula Carneiro & 0.289473684 \\
Capitão Antônio Teixeira Guimarães & 0.184210526 \\
Antônio Pedro Vidigal de Barros & 0.184210526 \\
João Pinto de Moraes Sarmento & 0.131578947 \\
Tereza Angélica Maria de Jesus & 0.078947368 \\
Antônio Martins Miranda & 0.078947368 \\
João Luiz Pinto & 0.078947368 \\
José Justiniano Carneiro & 0.078947368 \\
Tenente Antônio Teixeira Guimarães & 0.07894736 \\
João Antônio Barbosa & 0.026315789 \\
Antonio Nogueira de Pinho & 0.026315789 \\
Camilo José de Moura & 0.026315789 \\
Ana Maria Barbosa & 0.026315789 \\
Anacleto Gonçalves da Cunha & 0.026315789 \\
\hline
\end{tabular}

Fonte: Inventários post-mortem do AFP

Tabela 3 - Número de laços entre dois inventariados, Guarapiranga, 1830-1865

\begin{tabular}{|l|c|}
\hline Inventariado & Número de relações \\
\hline Francisca Januária de Paula Carneiro & 11 \\
Capitão Antônio Teixeira Guimarães & 7 \\
Antônio Pedro Vidigal de Barros & 7 \\
João Pinto de Moraes Sarmento & 5 \\
Tenente Antônio Teixeira Guimarães & 3 \\
Tereza Angélica Maria de Jesus & 3 \\
Antônio Martins Miranda & 3 \\
João Luiz Pinto & 3 \\
José Justiniano Carneiro & 3 \\
João Antônio Barbosa & 1 \\
Antonio Nogueira de Pinho & 1 \\
Camilo José de Moura & 1
\end{tabular}

\footnotetext{
${ }^{6} \mathrm{O}$ grau de centralidade de um ator dentro da rede é um número que varia de 0 a 1 , no qual quanto mais próximo de 1, maior a centralidade. A centralidade dos atores dessa rede é baixa, uma vez que esse grau foi calculado com base na rede geral, ou seja, calculado a partir de 39 indivíduos (vide imagem 4).
} 


\begin{tabular}{|l|c|}
\hline Inventariado & Número de relações \\
\hline Ana Maria Barbosa & 1 \\
Anacleto Gonçalves da Cunha & 1 \\
\hline
\end{tabular}

Fonte: Inventários post-mortem do AFP

Como se observa nas tabelas acima, Dona Francisca Januário de Paula Carneiro possuía um papel de destaque dentro dessa rede creditícia. Proveniente de uma família que não muito abastada, Francisca consegui ascender socialmente, até no momento de sua morte, e possuir uma das maiores riquezas da freguesia.

Filha do cirurgião Francisco Magalhães Canavazes e Tomásia Rosa Santos. Sua família era muito próxima dos Januário Carneiro, residindo inclusive no mesmo quarteirão. Ambas as famílias possuíam importância social na freguesia de Guarapiranga, uma vez que, na primeira metade do século XIX, elas se encontravam no centro das escolhas de batismo (Andrade, 2014). Segundo Manoela Pedroza, "os compadrios de uma mesma família abastada, direcionados para outras famílias de diferentes estratos sociais, foram, sabiamente, uma das estratégias das elites para a criação de redes clientelares e para a demonstração de seu prestígio" (Pedroza, 2009, p.67).

Nas listas nominativas de 1831, encontramos seus irmãos encabeçando fogos pequenos. Seu irmão mais velho, Antônio Magalhães Canavazes, tornou-se sucessor de seu pai no ofício de cirurgião, coabitando com sua esposa e seus 5 filhos, mas sem nenhum escravo. Sua irmã Germana Clara Lucinda, costureira e seu irmão Elias, sacristão, moram juntos com mais quatro escravos. Por fim suas irmãs Maria Apolônia e Maria Rosa aparecem casadas com pequenos lavradores, trabalhando em atividades vinculadas à indústria têxtil e o comércio desses produtos.

Casada no primeiro matrimônio com José Tomás Ferreira, com quem não teve filhos, ficou viúva logo em seguida. Casou-se então com Antônio Januário Carneiro, irmão do Coronel José Justiniano Carneiro, com quem tem 10 filhos. No entanto ela se torna viúva pela segunda vez em 1828. Segundo Raquel Mendes Pinto Chequer,

Várias mulheres ficavam viúvas ainda jovens e a realização de um segundo casamento era frequente. Os núcleos familiares se expandiam com a chegada do esposo e, às vezes, de mais filhos. Estrategicamente falando, o casamento de viúvas poderia trazer vantagens, tanto para o segundo marido como para ela mesma. Viúvas que possuíam terra, casa e/ou escravos propiciavam aos homens segurança no empreendimento dos negócios e a chance de enriquecimento fácil. Por outro lado, um novo chefe de família significava a possibilidade de agregar trabalho e, consequentemente, gerar mais renda e tranquilidade financeira à unidade domestica. (Chequer, 2002, p. 84) 
Imagem 3 - Genealogia de Francisca Januário de Paula Carneiro.

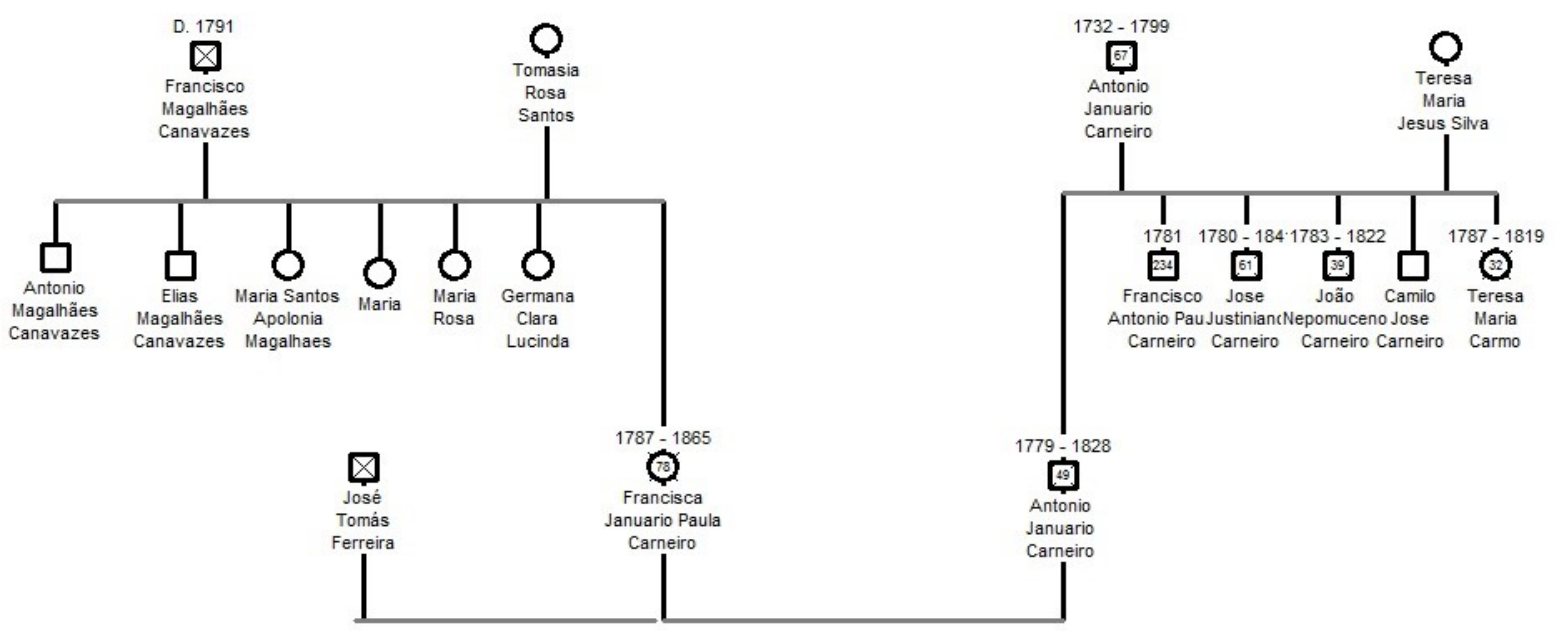

Fonte: Inventário post-mortem de Francisca Januário de Paula Carneiro. AFP Caixa A037, Auto 496.

De acordo com a lei da herança, metade dos bens do falecido ficaria para a esposa, a outra metade ficaria para os herdeiros e também para pagar as despesas com inventário e funeral. O seu primeiro casamento não the rendeu bens significativos, no entanto. Com a morte de seu segundo marido, o espólio de seu inventário contribui para o enriquecimento da viúva. No entanto, Francisca não se contentou apenas com a herança recebida de seus maridos. De acordo com Raquel Mendes Pinto Chequer (2002, p. 99) "a confiança que os maridos demonstravam ter nas suas esposas para administrar o patrimônio da família não era apenas parte de um discurso que visava garantir a posse dos bens à mulher. De fato, algumas mulheres pareciam possuir condições e quesitos necessários para bem gerirem os negócios da família".

Ficando viúva em 1828, Dona Francisca Januário de Paula Carneiro aparece nas listas nominativas de 1831, como negociante e chefe de fogo, coabitado por seus nove filhos e dezessete escravos. Diferentemente do que observa Bacellar, analisando a sociedade sorocabana dos séculos XVIII e XIX, onde as viúvas chefes de domicílio viviam com base na economia informal sendo "perceptível que muitas dessas viviam no limiar entre a pobreza e a miséria. Em diversos domicílios, surge uma mulher extremamente despossuída, que tinha para declarar apenas seu trabalho manual e mais nada" (Bacellar, 2001, p. 167); Francisca Januário de Paula Carneiro consegue constituir uma grande fortuna.

Em seu inventário, são arroladas além da Loja de Fazenda Seca no distrito da Vila de Piranga, consta também: $2 / 3$ partes nas casas de sobrado perto da matriz (533\$320); $1 / 20$ parte das mesmas casas, compradas ao Tenente Coronel Joaquim Antonio Carneiro (40\$000); $2 / 3$ partes das casas imediatas a essa, ao pé da matriz (466\$666); $1 / 20$ parte das mesmas casas, compradas ao Tenente Coronel Joaquim Antonio Carneiro ( $35 \$ 000)$; $2 / 3$ partes da casa da Ladeira (466\$666); $1 / 20$ parte das mesmas, compradas ao mesmo (35\$000); Um terreno que fica entre a casa do Furriel (20\$000); $1 / 2$ das casas no Beco que vai para o Cascalho (200\$000); A casa onde esteve 
a Botica (100\$000); Uma chácara com casas de sobrado na rua do Rosario (800\$000);

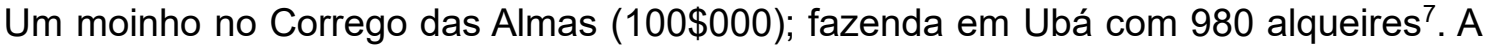
composição da riqueza de Francisca Januária Carneiro se concentra, principalmente, nas dívidas (35\%), seguido pelos bens de raiz (30\%), escravos $(19 \%)$, móveis $(15 \%)$ e animais $(1 \%)$.

Gráfico 1 - Composição da riqueza de Francisca Januário Carneiro.

Fonte: Inventário post-mortem de Francisca Januário de Paula Carneiro. AFP Caixa A037, Auto 496, 1865.

Francisca possuía 140 dívidas ativas, só que diferentemente do Coronel José Justiniano Carneiro, a média destas era $153 \$ 031$. Pouco mais de $10 \%$ dos seus devedores possuíam algum tipo de patente/título. Como os valores das dívidas, geralmente não ultrapassavam $100 \$ 000$, e a maioria dos seus credores são pessoas que não estão inseridos na elite guarapiranguense, infere-se que a atividade creditícia da Dona Francisca Januário de Paula Carneiro estava ligada às dívidas feitas em sua venda, assim como também devido à sua proeminência social dentro da freguesia.

Devido ao fato de seu inventário ter sido feito quase 35 anos após a realização das listas nominativas, e de não conter informações sobre a ocupação dos indivíduos, não será possível analisar o perfil dos seus credores, assim como a localidade onde residem. O que é passível de análise são os núcleos familiares aos quais esses indivíduos estão inseridos. Endossando que além das estratégias familiares o crédito é uma forma de interação e integração social, no inventário de Dona Francisca Januário de Paula Carneiro, encontram-se na condição de credores, membros das famílias Teixeira Guimarães, Alves Moreira.

A sua rede social se constitui como uma das mais densas e complexas que foi possível estabelecer entre os atores da freguesia de Guarapiranga. A densidade dessa rede é de 0,09259. O grau de centralidade da Dona Francisca Januário de Paula Carneiro é de 0,70833 . Dentro dessa rede, Dona Francisca se constitui como atriz central, se relacionando, de forma indireta, com vários outros atores centrais da freguesia, assim como vários outros menos proeminentes. A partir da Tabela 15,

\footnotetext{
${ }^{7}$ Inventário post-mortem de Francisca Januário de Paula Carneiro. AFP Caixa A037, Auto 496, 1865.
} 
percebemos que tanto Francisca quanto outros atores discutidos ao longo desse capítulo possuem posição de destaque dentro da rede.

Analisando a Imagem 4, percebe-se que os atores centrais possuem mais de um credor em comum com Dona Francisca. Existiam alguns indivíduos que se endividavam com vários desses atores ao longo dos anos. Como exemplo pode-se citar o caso de Antônio Alves Pereira, que na lista nominativa de 1831/32 aparece como carpinteiro do distrito de Calambau. Ele contraiu dívidas com João Pinto de Moras Samento, José Justiniano Carneiro, Francisca Januário de Paula Carneiro e com Tenente Antônio Teixeira Guimarães.

Diferentemente dos demais casos analisados para a freguesia de Guarapiranga, a Dona Francisca possuía dívidas passivas. O montante era de 29:792\$088. No entanto essas dívidas foram estabelecidas com seus herdeiros. Essas dívidas podem ser provenientes do espólio da partilha das terras do seu marido, como forma de manutenção do patrimônio e da riqueza, ou também relativas à compra e venda de imóveis ao longo de sua vida, assim como também a dissolução da sociedade comercial entre a falecida e os filhos Camilo Januario Carneiro, Antonio Januario Carneiro e Francisco Januario Carneiro, no valor de 55:398\$660:

Diz o Coronel Camillo Antônio Januário Carneiro, testamenteiro, um dos herdeiros e inventariante dos bens de sua falecida mãe D. Francisca Januária de Paula Carneiro, que ele suplicante tece com ela sociedade comercial, que existiu até a sua morte, depois da qual foi a mesma dissolvida entre o suplicante e os herdeiros Coronel Antônio Januário Carneiro e o Tenente Coronel Francisco Antônio Januário Carneiro, com os quais o suplicante fez a liquidação da mesma sociedade ${ }^{8}$.

Imagem 4 - Rede de credores de Francisca Januário de Paula Carneiro

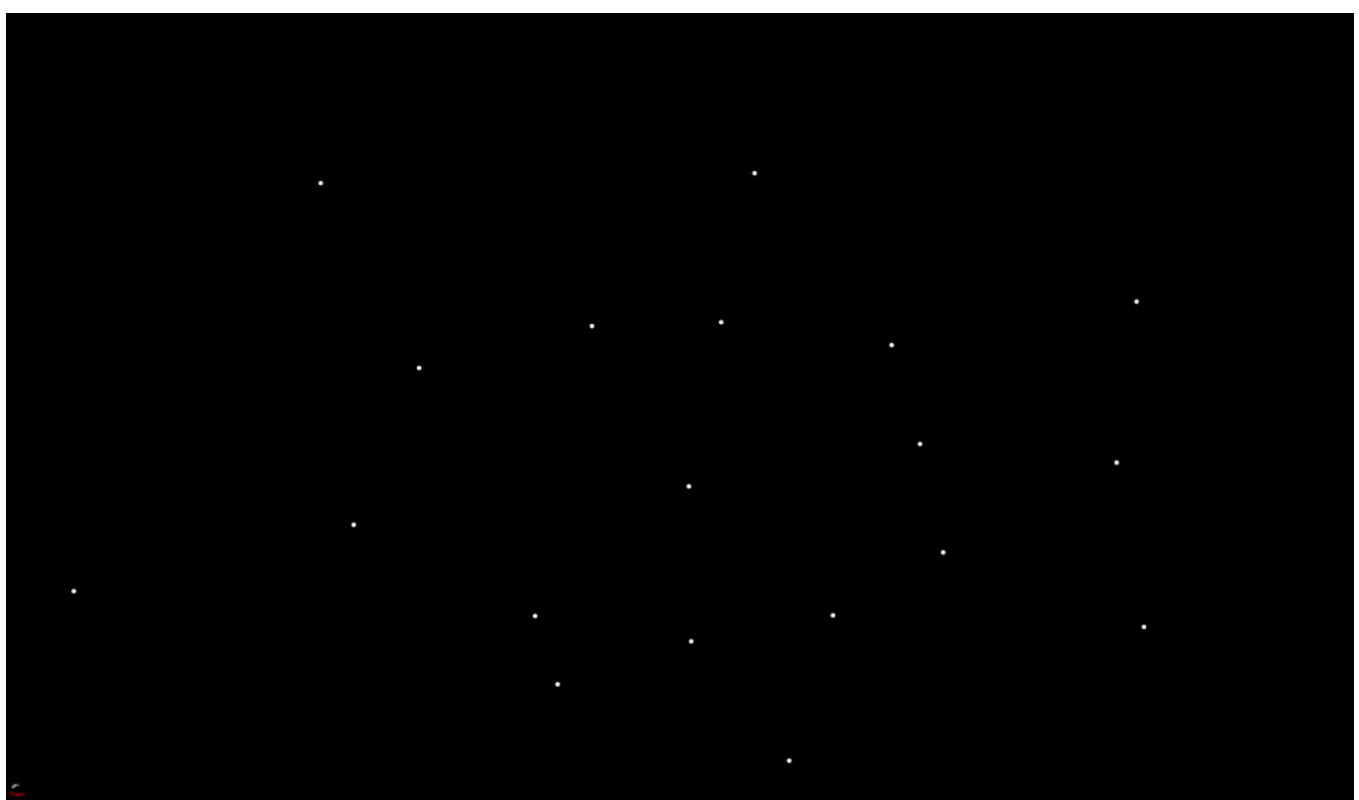

Fonte: Inventário post-mortem de Francisca Januário de Paula Carneiro. AFP Caixa A037, Auto 496, 1865.

Analisando a rede de crédito de Dona Francisca, percebe-se que ela se encontrava no centro dessa rede creditícia. De uma mulher proveniente de uma família

8 Inventário post-mortem de Francisca Januário de Paula Carneiro. AFP Caixa A037, Auto 496, folha 139/140, 1865. 
humilde em pouco mais de 30 anos, por méritos próprios ela se torna uma das pessoas mais ricas e influentes da Zona da Mata mineira, contendo em seu inventário mais de 140 contos de réis.

\section{Referências}

ANDRADE, Mateus Rezende de. Compadrio e Família em zona de fronteira agrícola: as redes sociais da elite escravista, freguesia de Guarapiranga (c1760-c1850). Janeiro de 2014. Dissertação (Mestrado em História). Universidade Federal de Minas Gerais. Belo Horizonte. 2014.

ANDRADE, Mateus Rezende de, LEMOS, GUSTHAVO. "Terras de compadres: família e enraizamento social em Guarapiranga, séculos XVIII e XIX." In: BOTELHO, Tarcísio Rodrigues, ANDRADE, Mateus Rezende de, LEMOS, Gusthavo (orgs.). Redes sociais e história. Belo Horizonte: Veredas \& Cenários, 2013, p. 51-88.

BACELLAR, Carlos de Almeida Prado. Viver e sobreviver em uma vila colonial: Sorocaba, séculos XVIII e XIX. São Paulo: Annablume/Fapesp. 2001

BLOCH, Marc. A apologia da História ou o ofício do historiador. Tradução André Telles. Rio de Janeiro: Jorge Zahar Ed. 2001

BRAUDEL Fernand. A identidade da França: Espaço e História; tradução Lygia Araújo Watanabe. - Rio de Janeiro: Globo, 1989.

CARVALHO, Enaile Flauzina. "Negociantes e redes de crédito: relações financeiras no Espírito Santo 1808-1818”. In: BOTELHO, Tarcísio Rodrigues, ANDRADE, Mateus Rezende de; LEMOS, Gusthavo (orgs.) Redes sociais e história. Belo Horizonte: Veredas \& Cenários, 2013. p. 143-187

CUNHA, Alexandre Mendes. "O urbano e o rural em Minas Gerais entre os séculos XVIII e XIX". In: Caderno da Escola do Legislativo. Belo Horizonte. Vol. 11 n. 16. Jan/jun. 2009.

CHEQUER, Raquel Mendes Pinto. Negócios de família, gerência de viúvas. Senhoras administradoras de bens e de pessoas (Minas Gerais 1750-1800). 2002, Dissertação (Mestrado em História). Universidade Federal de Minas Gerais. Belo Horizonte. 2002.

FONSECA, Cláudia Damasceno. Arraiais e Vilas d'el Rei: espaço e poder nas Minas Setecentistas. Belo Horizonte: Editora UFMG, 2011.

GRAÇA FILHO, Afonso de Alencastro. A princesa do Oeste e o mito da decadência de Minas Gerais: São João del-Rei (1831-1888). São Paulo: Annablume. 2002.

HAESBAERT, Rogério. Territórios alternativos. Niterói: EDUFF; São Paulo, Contexto. 2002.

HISSA, Cássio Eduardo Viana. A mobilidade das fronteiras: inserções da geografia na crise da modernidade. Belo Horizonte: Editora UFMG, 2002.

HOLANDA, Sérgio Buarque de. Caminhos e Fronteiras. Rio de Janeiro: José Olympio; Departamento de Cultura da Guanabara 2a Edição. 1975.

LEMOS, Gusthavo. Aguardenteiros do Piranga: família, produção da riqueza e dinâmica do espaço em zona de fronteira agrícola. Minas Gerais: 1800-1856. 2012. Dissertação 
(Mestrado em História). Universidade Federal de Minas Gerais. Belo Horizonte. 2012.

LIBBY, Douglas Cole. Transformação e trabalho em uma economia escravista: Minas Gerais no século XIX. São Paulo, Editora Brasiliense 1988.

MARTINS, Roberto Borges. Economia escravista de Minas Gerais no século XIX. Texto para discussão nº10. CEDEPLAR 1982.

MENDES, Fábio Faria. Redes sociais, sucessão e herança (1780-1880). Relatório Final (FAPEMIG). Viçosa 2011.

MENESES, José Newton Coelho. "Escalas espaço-temporais e história cultural: uma reflexão sobre o espaço como categoria de análise". IN: PAIVA, Eduardo França Márcia Amantino; Isnara Pereira Ivo. (Org.). Escravidão, Mestiçagens, Ambientes, Paisagens e espaços. 1ed.São Paulo: Annablume, 2011, v. 3, p. 55-79.

PAIVA, Clotilde ARNAUT, Luiz D. H. "Fontes para o estudo de Minas Oitocentista: Listas Nominativas". In: V Seminário sobre economia mineira. Anais. Belo Horizonte: UFMG/CEDEPLAR, 1990.

PEDROZA, Manoela. Engenhocas da moral: redes de parentela, transmissão de terras e direitos de propriedade na freguesia de Campo Grande (Rio de Janeiro, século XIX). Rio de Janeiro: Arquivo Nacional, 2011.

WASSERMAN, Stanley \& FAUST, Katerine. Social Network analysis: methods and applications. New York: Cambridge University Press. 1994.

\section{Notas de autoria}

Rodrigo Paulinelli de Almeida Costa é graduado em História pela Universidade Federal de Viçosa. Mestre em História pela Universidade Federal de Minas Gerais, com financiamento da FAPEMIG, estudando as relações creditícias na freguesia de Guarapiranga - MG entre os anos de 1830-1865. Doutorando em História pela Universidade Federal de Minas Gerais, desenvolvendo pesquisa na área da formação do espaço mineiro a partir da distribuição de sesmarias entre os anos de 1701 e 1836. E-mail: rodrigopaulinelli16@gmail.com.

\section{Como citar esse artigo de acordo com as normas da revista}

COSTA, Rodrigo Paulinelli de Almeida. O papel das mulheres no sistema creditício da freguesia de Guarapiranga: o caso de Dona Francisca Januária de Paula Carneiro. Sæculum - Revista de História, v. 24, n 41, p. 408-425, 2019.

\section{Contribuição de autoria}

Não se aplica.

\section{Consentimento de uso de imagem}

Não se aplica.

\section{Aprovação de comitê de ética em pesquisa}

Não se aplica.

\section{Licença de uso}

Este artigo está licenciado sob a Licença Creative Commons CC-BY. Com essa licença você pode compartilhar, adaptar, criar para qualquer fim, desde que atribua a autoria da obra. 
Histórico

Recebido em 15/03/2019.

Aprovado em 30/09/2019. 